\title{
Photosynthetic machinery and antioxidant status of wheat genotypes under drought stress followed by rewatering
}

\author{
D.R. ALIYEVA*, L.M. AYDINLI*, A.N. PASHAYEVA*, I.S. ZULFUGAROV ${ }^{* * * * * * *}$, \\ and I.M. HUSEYNOVA*,+ \\ Institute of Molecular Biology and Biotechnologies, Azerbaijan National Academy of Sciences, 11 Izzat Nabiyev Str., \\ Baku AZ 1073, Azerbaijan* \\ Department of Integrated Biological Science and Department of Molecular Biology, Pusan National University, \\ Busan 46241, Korea** \\ Department of Biology, North-Eastern Federal University, 58 Belinsky Str., Yakutsk 677-027, Republic of Sakha \\ (Yakutia), Russian Federation ${ }^{* * *}$
}

\begin{abstract}
Land plants shorten their vegetation period during water deficiency. Under water stress, wheat plants undergo several changes at the morphophysiological level. We tried to elucidate the role of the morphophysiological parameters and the photosynthetic machinery in response to drought followed by rewatering. Therefore, some morphophysiological traits of two bread wheat genotypes (drought-tolerant Gobustan, drought-sensitive Tale 38) were studied. The $\mathrm{H}_{2} \mathrm{O}_{2}$ content increased under drought in both genotypes but recovered in the Gobustan genotype after rewatering. The isozymes of peroxidase manifested dynamic changes under drought. The electron transport rate and the maximum photochemical quantum efficiency of PSII showed similar responses to drought with subsequent rewatering in both genotypes. However, the amount of the photosynthetic pigments changed drastically resulting in structural changes of thylakoid membranes. In Gobustan, the thylakoid membrane structure almost completely recovered after rewatering. Thus, the drought-tolerant genotype shows a more dynamic response of photosynthetic machinery and antioxidant capacity.
\end{abstract}

Keywords: benzidine peroxidase; reactive oxygen species; thylakoid membrane; Triticum aestivum L.

\section{Introduction}

According to the data of IPCC (Intergovernmental Panel on Climate Change), the earth temperature will rise by an average of $1.1-6.4^{\circ} \mathrm{C}$ by the end of the $21^{\text {st }}$ century. Increasing the temperature by $3^{\circ} \mathrm{C}$ will drastically reduce the carbon content of green plants by limiting natural carbon sources. The drought areas may increase from 1 to $3 \%$ by 2100 , due to increased evaporation, which may lead to further limitation of the structure and function of the terrestrial ecosystem. Drought stress is one of the superiorities of climate change that has a negative impact on wheat growth and yield (Marček et al. 2019, Sallam et al. 2019). Strategically important bread wheat varieties cultivated in Azerbaijan are affected by stress due to climate change leading to the decline in productivity of agricultural plants, which is considered to be one of the major agricultural problems, exacerbated by global warming (Wei et al. 2017).
The ability of plants to shorten their vegetation period during water deficiency is considered to be a very important indicator for agricultural plants. Under stress, the plant undergoes various morphological, physiological, biochemical, and molecular changes (Pandey et al. 2015). The rate of $\mathrm{CO}_{2}$ assimilation decreases as the stomatal conductance weakens under drought stress. Under drought, the plant leaves shrink, and the diameter of the stem diminishes, water-use efficiency decreases due to the weakened plant-water exchange. Plant height and productivity decrease due to the decline in photosynthetic pigments and gas exchange. Almost all environmental stresses including drought cause a reduction in $\mathrm{CO}_{2}$ fixation and as a consequence, the Calvin-BensonBassham cycle cannot regenerate $\mathrm{NADP}^{+}$efficiently. It causes an overreduction of the photosynthetic electron transport chain, which generates more reactive oxygen species (ROS), such as singlet oxygen, superoxide anion radical, and hydrogen peroxide, in the chloroplasts

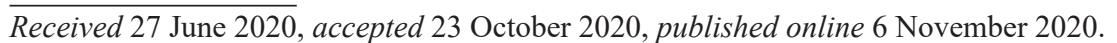

${ }^{+}$Corresponding author; fax: +99412 510 2433, e-mail: i.huseynova@imbb.science.az, i_guseinova@mail.ru

Abbreviations: $\mathrm{BPO}$ - benzidine peroxidase; ETR - electron transport rate; $\mathrm{F}_{\mathrm{v}} / \mathrm{F}_{\mathrm{m}}-$ the maximum photochemical quantum efficiency of PSII; ROS - reactive oxygen species; RWC - relative water content; WUE - water-use efficiency; $\beta$-DM - n-dodecyl $\beta$-D-maltoside. Acknowledgments: This work was supported by the Science Development Foundation under the President of the Republic of Azerbaijan Grant no. EIF-KETPL-2-2015-1(25) - 56/35/3. Authors are grateful to Prof. Tibor Janda (Agricultural Institute, Centre for Agricultural Research, Hungary) for critical reading of the manuscript and insightful comments. The authors would also like to acknowledge the valuable comments and recommendations of the reviewers to the current work.

Conflict of interest: The authors declare that they have no conflict of interest. 
(Zulfugarov et al. 2011). When photosynthesis is limited under stress, reaction centers are extremely reduced leading to the accumulation of additional energy harmful to PSII (Demmig-Adams and Adams 1992) and synthesis of ROS in the chloroplasts (Smirnoff 1993). There is a positive correlation between the rate of photosynthesis and the content of chlorophylls (Chl), the main components of the chloroplasts (Amirjani and Mahdiyeh 2013). The inhibition of photosynthesis is the result of decreased $\mathrm{CO}_{2}$ assimilation due to low mesophyll and stomatal conductance or impaired carbohydrate metabolism under drought stress (Kalaji and Nalborczyk 1991, Haworth et al. 2016).

Some physiological parameters, such as ROS generation and scavenging, relative water content (RWC), photosynthetic electron transport, and structural changes, are the physiological markers for estimating stress tolerance in plants. Relative water content, stomatal resistance, transpiration rate, and leaf temperature are significant parameters influencing water metabolism in plants. RWC is related to water absorption through roots and water loss by transpiration. The accumulation of ROS in the plants exposed to adverse environmental conditions is the early response of the cell to abiotic stresses. Drought and high temperatures cause oxidative damage in proteins, DNA, and lipids in plant cells leading to a sharp increase in the ROS content (Farooq et al. 2009, Gill and Tuteja 2010). Enzymatic and nonenzymatic components of the antioxidant defense system play a crucial role in the elimination of ROS (Huseynova et al. 2014, Aliyeva et al. 2020).

The enzymatic components of the antioxidant defense system in plants, peroxidases, are considered as one of the stress indicators of plants because their activities considerably increase after stress stimulation. Plant peroxidases have been implicated in various plant growth and developmental processes, such as cell wall metabolism, defense against pathogens (Passardi et al. 2005), fruit growth, and ripening (Andrews et al. 2002). Plant peroxidases have many physiological functions, such as immobilization of extension, construction of matrix polysaccharides, cell wall protection by the accumulation of lignin and suberin, pathogen protection, auxin catabolism, and synthesis of secondary metabolites (Tari and Csiszár 2003, De Gara 2004). Therefore, they can be considered physiological markers.

The light-regulated photosynthetic electron transport system transmits water electrons to NADP, creating a proton gradient that facilitates ATP synthesis. The main feature of PSII is its sensitivity to light, which results in oxidation of the D1 protein at the reaction center (KriegerLiszkay et al. 2008) and the formation of singlet oxygen (Vass and Cser 2009). Because of the sensitivity to light, the D1 protein, included in PSII, is initially damaged under stress. Limitations of the photosynthetic electron transport system occur when the balance between damage and recovery processes is disturbed and during photoinhibition (Vass 2012). At a high intensity, the recovery rate also rises, therefore, the regulation of the high PSII activity becomes possible (Foyer and Shigeoka 2011). In the early stages of drought, the stomatal closure can increase water-use efficiency (WUE), but as the drought deepens, dehydration of mesophyll cells inhibits photosynthesis. Phenotyping of photosynthesis is important to realize which physiological parameters limit the crop productivity in agricultural systems.

Drought is one of the dominant natural hazards that negatively affect dry mass accumulation, respiration rate, and wheat productivity (Huseynova et al. 2016). We chose local varieties Gobustan and Tale 38, which are productive and at the same time contrasting in their drought tolerance, as the objects of the study because of the increased attention paid to the cultivation of bread wheat varieties in these areas. In the present study, we compared several morphophysiological markers including RWC, dry biomass, leaf area, amounts of phenolic compounds, the photosynthetic responses using chlorophyll (Chl) fluorescence of chloroplasts, thylakoid membrane proteins, and the components of antioxidant system in two wheat genotypes differing in their tolerance during drought stress and rewatering. The goal of these analyses was to (1) find which changes have an important role in response to drought followed by recovery, (2) elucidate the role of the photosynthetic machinery in response to drought followed by recovery of two wheat genotypes contrasting in drought tolerance.

\section{Materials and methods}

Plant material: The field experiment was conducted during the 2019-2020 growing season at the research field of Plant Physiology and Biotechnology Department of Research Institute of Crop Husbandry, located in the Absheron peninsula, Baku, Azerbaijan. The seeds of two bread wheat genotypes (Gobustan and Tale 38) were planted at the end of October, at an average density of 400 seeds per $\mathrm{m}^{2}$, in two replications at $1 \times 10 \mathrm{~m}$ plots, consisting of seven rows placed $15 \mathrm{~cm}$ apart. Soil had a weak alkaline property at $0-75 \mathrm{~cm}$ depth with $\mathrm{pH}$ 8.6-8.9. Fertilizers were applied as $120 \mathrm{~kg}$ (nitrogen) per hectare (N120), $60 \mathrm{~kg}$ (phosphorus) per hectare (P60), $60 \mathrm{~kg}$ (potassium) per hectare (K60). This research was conducted on two local bread wheat (Triticum aestivum L.) genotypes contrasting for drought tolerance (Gobustan as drought-tolerant and Tale 38 as drought-sensitive) taken from Gene Pool of Research Institute of Crop Husbandry (Baku, Azerbaijan). Plants grew under natural field conditions and they were well irrigated to avoid any water stress. To realize the drought treatments, plants at the wax ripeness stage were subjected to one of the following irrigation regimes: control, a well-irrigated treatment (no drought stress), drought stress, imposed during the vegetative stage by withholding irrigation, and rewatering (after $7 \mathrm{~d}$ of rehydration). Control plants were irrigated at germination, stem extension, and grain-filling stages. Rehydration of nonirrigated plants was carried out only at the grain-filling stage, after strong dehydration of plants. The influence of drought on plants was identified visually, by determination of the relative water content in leaves, as well as the determination of the water content in the soil 
(Lambe and Whitman 1969). Soil water content was 60\% for control, $30 \%$ for drought, and $60 \%$ for rewatering state. Light intensity, temperature, and humidity were 50-1,500 $\mu$ mol(photon) $\mathrm{m}^{-2} \mathrm{~s}^{-1}, 36 \pm 3^{\circ} \mathrm{C}, 35 \pm 3 \%$, respectively, during sampling.

Relative water content (RWC) of control, droughttreated, and rewatered plants was determined in the leaves according to Turner (1981) and was calculated by the following formula: $\mathrm{RWC}=[(\mathrm{FM}-\mathrm{DM}) /(\mathrm{TM}-\mathrm{DM})] \times 100$, where FM - fresh mass, TM - turgid mass, DM - dry mass.

Dry mass content: The method is based on the drying of the weighed sample to a constant mass at $80 \pm 2{ }^{\circ} \mathrm{C}$. The content of the dried mass in the examined sample was expressed as a percentage of the initial sample mass. The dry mass content was determined using the following formula: $\mathrm{C}[\%]=(\mathrm{DM} / \mathrm{FM}) \times 100$.

Phenolic compounds: To quantify phenolic compounds accumulated in the cell, the method modified by Singleton and Rossi (1965) was used. The method is based on the reaction of phenols with the Folin-Ciocalteu reagent. The reagent is a mixture of salts of phosphotungstic acid and phosphomolybdenum and phenols form blue complexes with these salts in an alkaline medium, which allows performing the spectrophotometric determination. FolinCiocalteu reagent of $0.5 \mathrm{ml}$ was added to $0.1 \mathrm{ml}$ of the extract, and after $3 \mathrm{~min}, 0.4 \mathrm{ml}$ of $\mathrm{Na}_{2} \mathrm{CO}_{3}\left[75 \mathrm{~g} \mathrm{~L}^{-1}(\mathrm{w} / \mathrm{v})\right]$ was added, stirred well, and after $2 \mathrm{~h}$, the optical density was measured at $765 \mathrm{~nm}$ with spectrophotometer (Ultrospec 3300 PRO, Amersham, USA).

Hydrogen peroxide content was determined using the spectrophotometric method according to Bellincampi (2000) based on the oxidation of $\mathrm{Fe}^{2+}$ ions to $\mathrm{Fe}^{3+}$ with xylene orange. Optical density was determined at $560 \mathrm{~nm}$ in Thermo Scientific Evolution 350 UV-Vis spectrophotometer (England). Standards were prepared using $30 \% \mathrm{H}_{2} \mathrm{O}_{2}$.

Histochemical detection of $\mathbf{H}_{2} \mathbf{O}_{2}$ was conducted as described by Mahalingam et al. (2005). For hydrogen peroxide determination, detached leaves of the control, stress-exposed, and rewatered plants were placed in Petri plates with $5 \mathrm{mM}$ DAB containing $10 \mathrm{mM} \mathrm{MES}$ $(\mathrm{pH} 3.8)$. The cleared leaves were preserved in $50 \%$ ethanol-glycerol mixture and photographed.

Enzyme extraction: Leaf materials $(0.5 \mathrm{~g})$ were ground in liquid nitrogen and then homogenized in $100 \mathrm{mM}$ Na-phosphate ( $\mathrm{pH} 7.8$ ) buffer containing $1 \mathrm{mM}$ EDTA, $2 \mathrm{mM}$ PMSF, $1 \%$ PVP, and $0.1 \%$ Triton $X-100$. Then, the samples were centrifuged at $4^{\circ} \mathrm{C}$ for $20 \mathrm{~min}$ at $15,000 \times g$ and the obtained supernatants were used for the analysis of benzidine peroxidase (BPO, EC 1.11.1.7.).

Benzidine peroxidase activity: The activity of benzidinetype peroxidase was measured spectrophotometrically (Ultrospec 3300 PRO, Amersham, USA) by the increase in optical density of the reaction mixture for $1 \mathrm{~min}$ at
$590 \mathrm{~nm}$ as described in Gechev et al. (2002). Peroxidase activity was determined in a reaction mixture containing $50 \mathrm{mM}$ potassium phosphate buffer $(\mathrm{pH} 4.8), 20 \mathrm{mM}$ benzidine, $0.6 \mathrm{mM} \mathrm{H}_{2} \mathrm{O}_{2}$, and $30 \mu \mathrm{l}$ of enzyme preparation in a final volume of $1 \mathrm{ml}$. The activity was calculated in $\mu$ mol(benzidine product) $\mathrm{mg}^{-1}$ (protein) $\mathrm{min}^{-1}$ considering extinction coefficient $\varepsilon=39 \mathrm{mM}^{-1} \mathrm{~cm}^{-1}$.

Isoenzymes of benzidine peroxidase: Qualitative changes in the enzyme activity were determined using native polyacrylamide gel electrophoresis (PAGE) according to the method of Davis (1964). The enzyme extract in 50\% glycerol with $1 \%$ bromophenol blue was applied to the $8 \%$ polyacrylamide gel. Electrophoresis was carried out for $3 \mathrm{~h}$ at $4^{\circ} \mathrm{C}$ with a steady current of $30 \mathrm{~mA}$, using the device SE 250 (Amersham Biosciences, USA). Following electrophoretic separation, the gels were stained for different isoenzymes. The staining of benzidine peroxidase lines was performed by the method of Cuypers et al. (2002). For analysis of benzidine peroxidase isoenzymes, the gel was incubated for $1 \mathrm{~h}$ at room temperature in a solution containing $0.1 \mathrm{~g}$ of benzidine in $100 \mathrm{ml}$ of $0.2 \mathrm{M}$ sodium acetate buffer ( $\mathrm{pH} 5.0)$ and $2.5 \mathrm{ml}$ of $3 \% \mathrm{H}_{2} \mathrm{O}_{2}$ in $100 \mathrm{ml}$ of benzidine solution.

Photosynthetic pigments: The Chl content was determined by the method of Porra et al. (1989). Chl $a\left[\mathrm{nmol} \mathrm{ml} l^{-1}\right]=$ $14.21 \mathrm{~A}_{663}-3.01 \mathrm{~A}_{645}$, Chl $b\left[\mathrm{nmol} \mathrm{ml}{ }^{-1}\right]=25.23 \mathrm{~A}_{645}-$ $5.16 \mathrm{~A}_{663}, \mathrm{Chl}(a+b)\left[\mathrm{nmol} \mathrm{ml}^{-1}\right]=22.22 \mathrm{~A}_{645}-9.05 \mathrm{~A}_{663}$. The content of carotenoids was determined by the method of von Wettstein (1957). Carotenoids $\left[\mathrm{mg} \mathrm{L}^{-1}\right]=$ $4.695 \cdot \mathrm{A}_{440.5}-0.268 \mathrm{Chl}(a+b)$.

Photosynthetic electron transport rate and Chl fluorescence measurements: The photosynthetic electron transport rate was measured according to Oh et al. (2009) using a Clark-type oxygen electrode (OXYV1, Hansatech Instruments, UK) at $25^{\circ} \mathrm{C}$ in a basal medium containing $20 \mathrm{mM}$ Tris, $0.4 \mathrm{M}$ sucrose, $10 \mathrm{mM} \mathrm{NaCl}, 1 \mathrm{mM}$ ascorbate, $1 \mathrm{mM}$ EDTA and $0.1 \%$ polyethylene glycol (PEG) supplemented with $1 \mathrm{mM}$ methyl viologen (MV) and $1 \mathrm{mM}$ 2,6-dichlorophenolindophenol (DCPIP) for whole chain electron transport activity measurement.

The maximum photochemical quantum efficiency of PSII, expressed as the $\mathrm{F}_{\mathrm{v}} / \mathrm{F}_{\mathrm{m}}$ ratio was measured according to Zulfugarov et al. (2019) using a modulated fluorimeter (PAM 101, Waltz, Effeltrich, Germany). Before measuring the $\mathrm{F}_{\mathrm{m}}$, leaf segments of wheat plants were dark-adapted for $30 \mathrm{~min} . \mathrm{F}_{\mathrm{m}}$ was induced by a saturating pulse of white light $\left(0.8 \mathrm{~s} ; 5,000 \mu \mathrm{mol}(\right.$ photon $\left.) \mathrm{m}^{-2} \mathrm{~s}^{-1}\right) . \mathrm{F}_{\mathrm{m}}$ and $\mathrm{F} 0$ are defined as maximal and minimal fluorescence yield of a dark-adapted sample, with all PSII RCs fully closed or opened, respectively.

Wheat thylakoid membranes were isolated according to Huseynova et al. (2007) from fresh leaves. All procedures were performed at $4^{\circ} \mathrm{C}$ under dim light.

Blue native polyacrylamide gel electrophoresis (BNPAGE) was performed by a linear gradient of $4.5-13.5 \%$ separation gel and 4\% stacking gel using gradient gel 
assembly (Amersham Biosciences, Little Chalfont Bucks, UK). Electrophoresis was performed by $10 \mathrm{~mA}$ at $4^{\circ} \mathrm{C}$ for 35-40 min. As the blue running front moved about a half of the desired running distance, the cathode buffer, which became blue-colored, was removed from the upper chamber and replaced with a clear cathode buffer. The BN-PAGE stopped when the Coomassie Blue ran out of the bottom of the gel.

Statistical analysis: The statistical analysis was conducted based on Student's $t$-test. Differences in mean values were considered significant when the $P$-value was $<0.01,<0.05$.

\section{Results}

We investigated the effect of the drought with subsequent rewatering on physiological traits, such as RWC, dry biomass, leaf area, and the contents of phenolic compounds in two bread wheat with contrasting tolerance to drought. RWC is the most appropriate measure of plant water status in terms of the physiological consequence of cellular water deficit. We observed that during the drought, RWC in the Gobustan variety decreased by $\sim 15 \%$ compared to the control variant and recovered by $14 \%$ after rewatering (Fig. 1A). The Tale 38 variety lost $\sim 21 \%$ water under stress and recovered by $10 \%$ after rewatering (Fig. $1 A$ ). According to the statistical analysis, there was no marked difference between control and rehydrated variants of the Gobustan variety. The recovery rate of this variety was slightly higher compared to Tale 38 . Dry mass content is the most important parameter for the evaluation of plant material quality. We found that dry biomass decreased two times under water deficiency and recovered by $60 \%$ after rewatering in the Gobustan variety (Fig. $1 D)$, whereas in the Tale 38 genotype, dry mass content decreased 1.9 times under drought and recovered by $38 \%$ upon rewatering. The leaf areas of both genotypes decreased under drought $(25 \%$ in Gobustan and $23 \%$ in
Tale 38) and partially recovered upon rewatering (14\% in Gobustan and 4\% in Tale 38) approaching the control variant (Fig. $1 C$ ). Results of our experiments showed that the contents of phenolic compounds increased in both genotypes under drought then decreased in the tolerant Gobustan genotype reaching the initial state, whereas, in the Tale 38 genotype, it remained at the high level (Fig. 1B). These data show that changes in dry biomass and the contents of the phenolic compounds respond to the drought with subsequent rewatering more dynamically. Interestingly, both physiological traits showed a high recovery rate in the drought-tolerant Gobustan genotype.

Drought stress affects the accumulation of the ROS and especially the hydrogen peroxide content. The $\mathrm{H}_{2} \mathrm{O}_{2}$ content increased drastically in both genotypes under drought and then decreased after rewatering (Fig. 2A). The rate of decrease of the $\mathrm{H}_{2} \mathrm{O}_{2}$ content was very significant in the drought-tolerant Gobustan genotype, however, in Tale 38, the rate of decrease was very small. Because the amount of $\mathrm{H}_{2} \mathrm{O}_{2}$ is very critical for the plant growth, development, and stress response (Phillips and Ludidi 2017), we confirmed the contents of $\mathrm{H}_{2} \mathrm{O}_{2}$ by the histochemical staining. The histochemical detection of the $\mathrm{H}_{2} \mathrm{O}_{2}$ content showed similar results (Fig. 2B) with spectrophotometric data (Fig. 2A). In other words, the drought-tolerant Gobustan variety retained a more intensive recovering ability than the drought-sensitive Tale 38. As shown in Fig. 2, the content of $\mathrm{H}_{2} \mathrm{O}_{2}$ increased in wheat plants under drought stress compared with the control conditions. Thus, it should affect the antioxidant status of these plants.

Therefore, we determined the changes in the BPO activity by the spectrophotometric assay and the gel electrophoresis method. We found that the constitutive

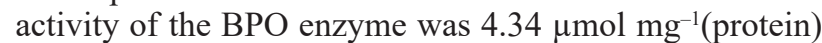

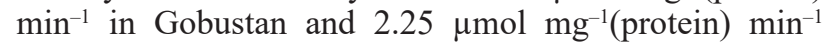
in Tale 38 genotypes (Fig. $3 A$ ). The enzyme activity decreased (1.5 and 1.2 times, respectively) under drought.

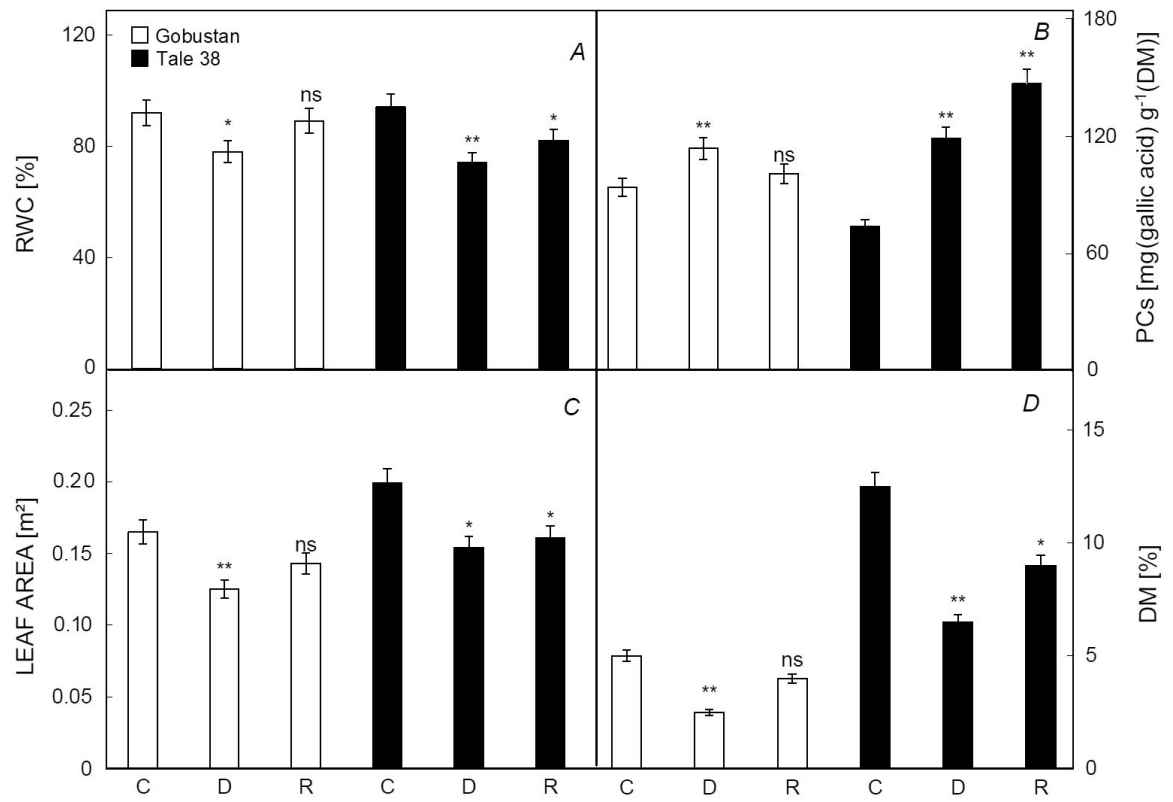

Fig. 1. Changes in $(A)$ relative water content (RWC), (B) amounts of phenolic compounds (PCs), $(C)$ leaf area, and $(D)$ dry mass $(\mathrm{DM})$ in bread wheat genotypes (Gobustan and Tale 38) during drought and rewatering periods at wax-ripeness stage of ontogenesis. C - control, D - drought, R - rewatering. Results of Student's $t$-test: ${ }^{* *},{ }^{*}$ - significance at the $0.01,0.05$ probability levels, respectively, ns - not significant. 

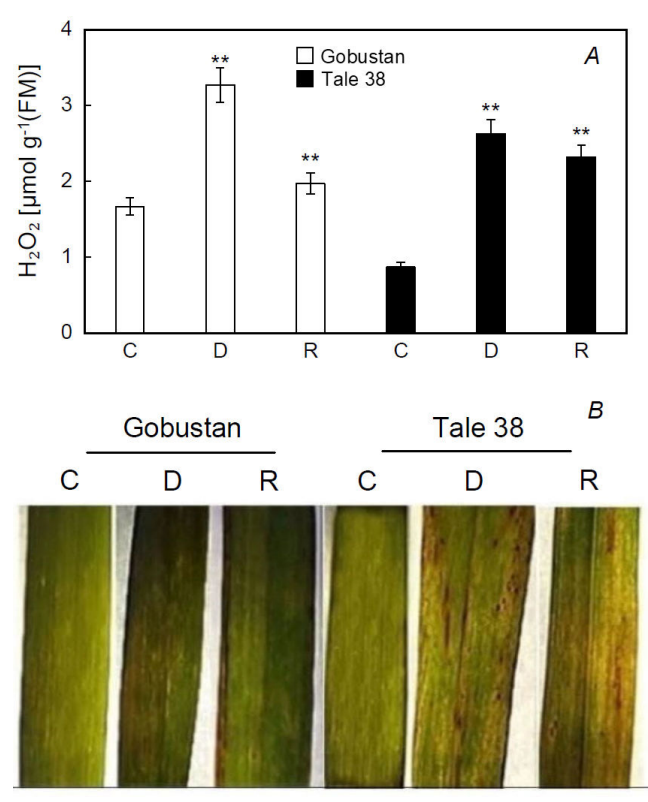

Fig. 2. Changes in $(A)$ amounts of hydrogen peroxide and $(B)$ histochemical staining of hydrogen peroxide in bread wheat genotypes (Gobustan and Tale 38) during drought and rehydration periods. $\mathrm{C}-$ control, $\mathrm{D}-$ drought, $\mathrm{R}-$ rewatering. Results of Student's $t$-test: ${ }^{* *},{ }^{*}-$ significance at the $0.01,0.05$ probability levels, respectively.

After rewatering, the BPO activity increased in both genotypes (1.3 and 1.1 times, respectively) compared to the drought-exposed plants and this increase was more pronounced in the Gobustan genotype. We applied native PAGE analysis to identify the isoenzyme content of benzidine peroxidase using crude enzyme extract obtained from leaf samples of the two bread wheat genotypes with contrasting tolerance to drought. We observed four isoforms of benzidine peroxidase (BPO1, BPO2, BPO3, $\mathrm{BPO} 4)$ for the Gobustan genotype and three isoforms (BPO1, BPO3, BPO4) for the Tale 38 genotype (Fig. 3B). In the drought-tolerant Gobustan genotype, due to the effects of drought, the intensity of the heavy-molecularmass isoform (BPO1) was reduced, and mediummolecular-mass isoforms (BPO2, BPO3) disappeared. After rewatering, the intensity of BPO1 isoform continued to decrease and the medium-molecular-mass isoforms (BPO2, BPO3) were recovered in the Gobustan genotype (Fig. 3B). However, we observed complicated data in drought-sensitive Tale 38 (Fig. $3 B$ ). Thus, due to the effects of drought, the intensity of the heavy-molecularmass isoform (BPO1) was reduced, and mediummolecular-mass isoform BPO3 disappeared, but the band of BPO2 isoform, absent in the control sample of Tale 38, appeared. After rewatering, the intensity of BPO1 and $\mathrm{BPO} 2$ isoforms continued to decrease and the mediummolecular-mass isoform BPO3 was recovered in the Tale 38 genotype (Fig. 3B). Interestingly, the synthesis of the low-molecular-mass isoform (BPO4) was not affected by drought, however, increased after rewatering in both investigated genotypes (Fig. $3 B$ ). These data, dynamic
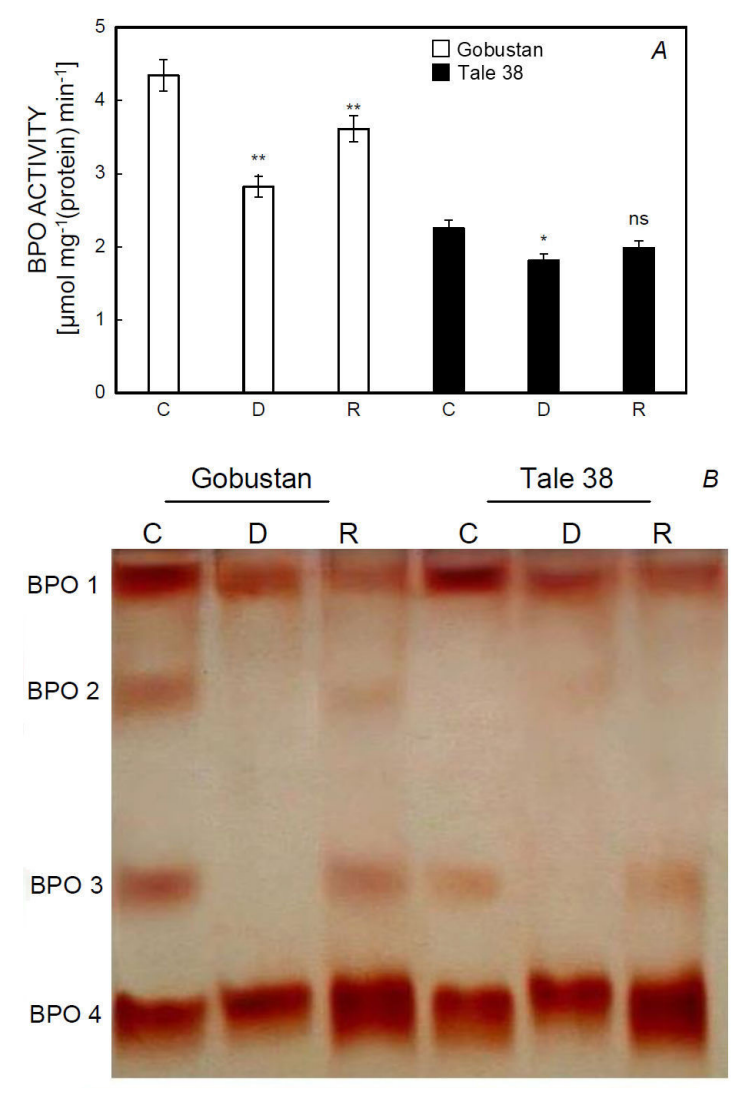

Fig. 3. Activity $(A)$ and isoenzyme content $(B)$ of benzidine peroxidase (BPO) in bread wheat genotypes (Gobustan and Tale 38) during drought and rewatering periods. C - control, $\mathrm{D}$ - drought, $\mathrm{R}$ - rewatering. A separating gel of $7 \%$ acrylamide was used for BPO analysis. To each slot, $30 \mu \mathrm{g}$ of proteins in $50 \%$ glycerol with $1 \%$ bromophenol blue were applied. Electrophoresis was carried out for $3 \mathrm{~h}$ at $4{ }^{\circ} \mathrm{C}$ with a steady current of $30 \mathrm{~mA}$. Results of Student's $t$-test: ${ }^{* *},{ }^{*}-$ significance at the $0.01,0.05$ probability levels, respectively, ns - not significant.

changes in the constitutive activity of the BPO enzyme and its isoforms, indicated that the antioxidant system of the Gobustan genotype functioned more efficiently.

The stomatal closure increases WUE at the beginning of drought, however, with time, dehydration of mesophyll cells inhibits photosynthesis (Haworth et al. 2016). Therefore, we first measured the electron transport rate (ETR) in chloroplasts isolated from two bread wheat genotypes. We found that ETR decreased in both varieties under drought and recovered after rewatering (Table 1). ETR decreased by 40 and $66 \%$ in the Gobustan and Tale 38 genotypes, respectively, after drought. After rewatering, ETR was recovered up to $80 \%$ in Gobustan and only around $70 \%$ in Tale 38 . More dynamic response to rehydration followed drought was observed in the Gobustan variety (Table 1). We observed similar behavior of the maximum photochemical quantum efficiency of PSII, expressed as the $F_{v} / F_{m}$ ratio, in both genotypes under all experimental conditions (Table 1). The statistical analysis shows that the rewatered samples did not differ significantly from control 
Table 1. Comparative statistical analysis of the electron transport rate (ETR), the maximum photochemical quantum efficiency of PSII $\left(F_{v} / F_{m}\right)$, and chlorophyll content in two bread wheat genotypes during drought and rewatering periods at wax-ripeness stage of ontogenesis. Means $\pm \mathrm{SD}$ of three replicates. Results of Student's $t$-test: ${ }^{* *},{ }^{*}-$ significance at the $0.01,0.05$ probability levels, respectively, ns - not significant.

\begin{tabular}{|c|c|c|c|c|c|c|}
\hline Genotypes & $\begin{array}{l}\text { ETR } \\
{\left[\mathrm{mmol}\left(\mathrm{O}_{2}\right) \mathrm{mg}^{-1}(\mathrm{Chl}) \mathrm{h}^{-1}\right]}\end{array}$ & $\mathrm{F}_{\mathrm{v}} / \mathrm{F}_{\mathrm{m}}$ & $\begin{array}{l}\mathrm{Chl} a \\
{\left[\mathrm{nmol} \mathrm{ml}^{-1}\right]}\end{array}$ & $\begin{array}{l}\mathrm{Chl} b \\
{\left[\mathrm{nmol} \mathrm{ml}^{-1}\right]}\end{array}$ & Chl $a / b$ & $\begin{array}{l}\text { Carotenoids } \\
{\left[\mathrm{mg} \mathrm{L}^{-1}\right]}\end{array}$ \\
\hline Gobustan control & $0.85 \pm 0.05$ & $0.811 \pm 0.041$ & $3.4 \pm 0.3$ & $1.3 \pm 0.1$ & $2.6 \pm 0.4$ & $4.4 \pm 0.1$ \\
\hline Gobustan drought & $0.51 \pm 0.04^{* *}$ & $0.746 \pm 0.037^{*}$ & $2.8 \pm 0.2^{*}$ & $1.1 \pm 0.1^{\mathrm{ns}}$ & $2.5 \pm 0.3^{* *}$ & $3.5 \pm 0.1^{* *}$ \\
\hline Gobustan rewatering & $0.67 \pm 0.05^{*}$ & $0.776 \pm 0.039^{\mathrm{ns}}$ & $3.0 \pm 0.2^{\mathrm{ns}}$ & $1.2 \pm 0.1^{\mathrm{ns}}$ & $2.5 \pm 0.3^{\mathrm{ns}}$ & $4.1 \pm 0.1^{* *}$ \\
\hline Tale 38 control & $1.91 \pm 0.07$ & $0.808 \pm 0.044$ & $3.9 \pm 0.3$ & $1.3 \pm 0.1$ & $3.0 \pm 0.4$ & $4.5 \pm 0.1$ \\
\hline Tale 38 drought & $0.65 \pm 0.05^{* *}$ & $0.771 \pm 0.039^{\mathrm{ns}}$ & $3.5 \pm 0.2^{*}$ & $1.2 \pm 0.1^{\mathrm{ns}}$ & $2.9 \pm 0.3^{\mathrm{ns}}$ & $3.2 \pm 0.1^{* *}$ \\
\hline Tale 38 rewatering & $1.37 \pm 0.07^{* *}$ & $0.796 \pm 0.043^{\mathrm{ns}}$ & $3.4 \pm 0.2^{\mathrm{ns}}$ & $1.1 \pm 0.1^{\mathrm{ns}}$ & $3.1 \pm 0.3^{\mathrm{ns}}$ & $3.7 \pm 0.1^{*}$ \\
\hline
\end{tabular}

variants. We observed that the amount of photosynthetic pigments decreased in both genotypes exposed to drought. However, after rewatering, the amount of the chlorophylls showed the tendency of recovering in the Gobustan genotype but not in the Tale 38 genotype. Under drought stress, the content of carotenoids decreased by 20 and $28 \%$ in the Gobustan and Tale 38 varieties, respectively. After rewatering, the recovery processes were more intensive in the tolerant variety compared to the sensitive one (6.8 and $17 \%$, respectively) (Table 1 ). Thus, the Gobustan variety maintained a high recovering ability.

The dynamic response of the photosynthetic pigments to drought and rewatering in two bread wheat genotypes was more significant than the response of the functional (ETR and $\mathrm{F}_{\mathrm{v}} / \mathrm{F}_{\mathrm{m}}$ ) parameters (Table 1). Therefore, to know how changes in the contents of photosynthetic pigments affect the photosynthetic machinery, we conducted experiments with thylakoid membranes using BN-PAGE.

As shown in Fig. 4, thylakoid membrane pigmentprotein complexes of the wheat genotypes were separated into six major pigment-protein complexes. We observed significant differences in the abundance of bands of pigment-protein complexes between treatments and genotypes. Quantification of the band intensity revealed that the PSII dimer and CP43-less PSII monomer band intensities increased after drought stress and then recovered after rewatering in the drought-tolerant Gobustan genotype, however, the more drastic changes occurred in the drought-susceptible Tale 38 genotype. Thus, except for the PSII dimer band, intensities of all other bands increased significantly after drought stress. Although, most of these band intensities recovered after rewatering, PSII dimer band intensity increased by $30 \%$. This might be due to the degradation of PSII, which caused a continuous decline in amounts of total chlorophylls even after rewatering in the drought-susceptible Tale 38 genotype (Table 1). The increased abundance of the PSII dimer could be associated with the deterioration of the photosynthetic organs of the drought-tolerant Gobustan genotype. Very weak bands of the supercomplexes might be due to the usage of the frozen thylakoids from aged leaves. Thus, these data showed that the photosynthetic machinery of the drought-tolerant Gobustan genotype exhibited a more dynamic response to the drought with subsequent rewatering.

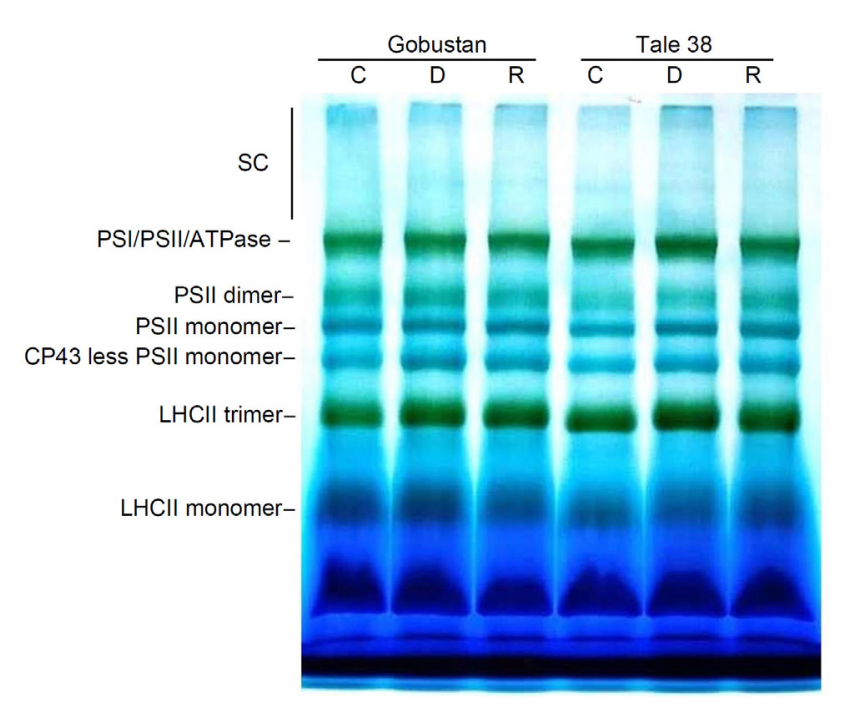

Fig. 4. Blue native polyacrylamide gel electrophoresis (BNPAGE) analysis of thylakoid membrane protein complexes from bread wheat genotypes. Frozen thylakoid membranes $(8 \mu \mathrm{g}$ of Chl) were solubilized with $1 \%$ n-dodecyl $\beta$-D-maltoside and separated by BN-PAGE. C - control, D - drought, $\mathrm{R}$ - rewatering. $\mathrm{SC}$ - supercomplexes.

\section{Discussion}

Currently, when cultivating wheat varieties, not only plant productivity, but also tolerance to changing environmental factors should be considered. Monitoring for changes in morphological, biochemical, and photosynthetic properties after drought and rewatering is important for developing drought-tolerant wheat genotypes adaptable to different environmental conditions. RWC is an important tolerance index signifying metabolic activity in tissues during dehydration. Being high during the first stages of plant development, this index decreases with increasing dry biomass (Amirjani and Mahdiyeh 2013). The leaf area ratio of a plant characterizes the relative size of its assimilatory organs, and therefore, it expresses the efficiency of the plant as a producer of leaf area. It can be used to indicate differences between plants based on genetic factors, the environment, or different treatments. The effect of drought was attenuated in a perennial herbaceous plant (Leymus 
chinensis), due to the water preserving mechanisms, such as stomatal closure and reduced leaf area (Xu et al. 2009). Our findings (Fig. 1) are in agreement with these published data. Significant reduction in the amount of chlorophylls (Table 1) and chlorophyll synthesis may be due to factors for which the structure is changed. An increase in the PSII dimer and CP43-less PSII monomer band intensities after drought stress (Fig. 4) indicates that drought changed the structure of thylakoid membranes in both tolerant and sensitive genotypes but the recovery rate was much higher in the drought-tolerant genotype. This indicates that dewatering may affect chlorophyll metabolism of drought-tolerant cultivars. Under stress, leaf expansion, associated with changes in leaf anatomy (smaller and thicker leaves), is reduced, resulting in higher chloroplast density per unit leaf area (Dąbrowski et al. 2015), which can lead to a reduction in photosynthesis as measured on a unit chlorophyll basis (Munns and Tester 2008). The stomatal closure under water deficiency is the plant primary response to drought stress. Generation of hydrogen peroxide at high concentrations under drought in wheat genotypes (Fig. 2) indicated that both genotypes attempt to avoid the stomatal closure. Hydrogen peroxide is able to alleviate the effect of drought through intensification of the ABA synthesis (Phillips and Ludidi 2017). A decrease in the photosynthetic efficiency, stomatal closure, and reduced leaf area resulted in the decrease in dry biomass of drought-exposed sugarcane (Saccharum officinarum L.) (Jangpromma et al. 2012), chickpea (Cicer arietinum L.) (Krouma 2010), and almond (Prunus mongolica) plants (Guo et al. 2015).

Increased antioxidant enzyme activity and content of nonenzymatic antioxidants lead to the upregulation of ROS-scavenging processes in plants. The contrasting ability of plants to overcome drought stress and recover after rewatering is attributed to the severity of drought stress and genotypic differences. Changes in metabolism and formation of the secondary metabolites such as phenolic compounds facilitate the control over abiotic stress. To protect plants from the harmful effects of ROS, phenolic compounds intensify the effect of antioxidant enzymes by decreasing the effect of chelating ions of metals (Tsao 2010). Changes in metabolism and synthesis of the secondary metabolites in plants occur mainly due to the peroxidation of cell membrane lipids by ROS. Amounts of phenols were found to increase by $10 \%$ compared with the control variant in Hypericum brasiliense exposed to drought (De Abreu and Mazzafera 2005). Pisum sativum, which is a representative of the leguminous family manifested similar results under drought (Nogués 1998). Peroxidases are known to be also involved in the biosynthesis of phenolic lignins (Sivakami et al. 2017). As they are antioxidants, it is possible to assess plant tolerance against drought during the early stages of plant development by determining peroxidase activity, thus, contributing to the acceleration of the selection process. Our results are consistent with the literature. It has been suggested that ROS function as molecular signals, inducing defense genes (Hernández et al. 2006). Different regulation of the BPO isozymes in different genotypes and under different experimental conditions (Fig. 3B) indicates that they are encoded by different alleles or separate genetic loci. Thus, future investigations may elucidate the functions of BPO isoforms.

Due to the high level of sensitivity, photosynthesis can be limited by different environmental factors. According to previous reports, leaf anatomy highly specializes in light absorption (Terashima et al. 2011). The research performed in leaves of the apple tree (Wang et al. 2018) and bread wheat genotypes (Zivcak et al. 2013, Dąbrowski et al. 2019) showed that drought stress caused the attenuation of ETR in PSII. As stresses cause chlorophyll loss, changes in total chlorophyll/carotenoids ratio may be used as an indicator of stress in plants. According to previous studies, the weakening chlorophyll synthesis or its rapid degradation under drought stress resulted in decreased chlorophyll content (Ashraf 2003). The research performed with soybean (Glycine max L.) plants showed that the chlorophyll amount and relative water content decreased under drought that partially recovered upon rehydration (Dong et al. 2019). The results of our research are in line with the above-mentioned publications and may help to identify the physiological traits that can play a vital role in drought tolerance and clarify the mechanism that occurs in crop plants during drought.

Conclusion: We observed that dynamic interactions between the ROS produced by drought stress, the antioxidant system, and the structure and composition of the thylakoid membranes are important for the regulation of photosynthesis under drought stress in bread wheat. Our findings suggested that rehydration recovers photosynthetic machinery of the drought-tolerant genotype almost completely, whereas recovery of the droughtsensitive genotype proceeds slowly. It opens a new path of robust testing of crop plant genotypes regarding their sensitivity to drought stress in terms of photosynthetic apparatus. We noticed that significant changes concern mainly ROS production (Fig. 2), pigment content (Table 1), and redistribution of the pigment-protein complexes in thylakoid membranes (Fig. 4). Our results allow us to conclude that the drought-tolerant genotype exhibits higher adaptive potential to stress and more dynamic recovery compared to the drought-sensitive genotype. Among the physiological traits used in this research the changes in dry biomass, the contents of the phenolic compounds, the content of $\mathrm{H}_{2} \mathrm{O}_{2}$, BPO enzyme, the amount of the photosynthetic pigments, and the proteome of thylakoid membranes respond to the drought with subsequent rewatering more dynamically. Interestingly, these physiological traits show a high recovery rate in the drought-tolerant Gobustan genotype.

\section{References}

Aliyeva D.R., Aydinli L.M., Zulfugarov I.S., Huseynova I.M.: Diurnal changes of the ascorbate-glutathione cycle components in wheat genotypes exposed to drought. - Funct. Plant Biol. 47: 998-1006, 2020.

Amirjani M.R., Mahdiyeh M.: Antioxidative and biochemical responses of wheat to drought stress. - ARPN J. Agric. Biol. Sci. 8: 291-301, 2013. 
Andrews J., Adams S.R., Burton K.S., Evered C.E.: Subcellular localization of peroxidase in tomato fruit skin and the possible implications for the regulation of fruit growth. J. Exp. Bot. 53: 2185-2191, 2002.

Ashraf M.: Relationships between leaf gas exchange characteristics and growth of differently adapted populations of blue panicgrass (Panicum antidotale Retz.) under salinity or water logging. - Plant Sci. 165: 69-75, 2003.

Bellincampi D., Dipierro N., Salvi G. et al.: Extracellular $\mathrm{H}_{2} \mathrm{O}_{2}$ induced by oligogalacturonides is not involved in the inhibition of the auxin-regulated rolB gene expression in tobacco leaf explants. - Plant Physiol. 122: 379-385, 2000.

Cuypers A., Vangronsveld J., Clijsters H.: Peroxidases in roots and primary leaves of Phaseolus vulgaris. Copper and zinc phytotoxicity: A comparison. - J. Plant Physiol. 159: 869-876, 2002.

Dąbrowski P., Baczewska-Dąbrowska A.H., Kalaji M.H. et al.: Exploration of chlorophyll $a$ fluorescence and plant gas exchange parameters as indicators of drought tolerance in perennial ryegrass. - Sensors-Basel 19: 2736, 2019.

Dąbrowski P., Pawluśkiewicz B., Baczewska-Dąbrowska A.H. et al:: Chlorophyll a fluorescence of perennial ryegrass (Lolium perenne L.) varieties under long term exposure to shade. - Zemdirbyste 102: 305-312, 2015.

Davis B.: Disc electrophoresis. II. Method and application to human serum proteins. - Ann. N.Y. Acad. Sci. 121: 404-427, 1964.

De Abreu I.N., Mazzafera P.: Effect of water and temperature stress on the content of active constituents of Hypericum Brasiliense Choisy. - Plant Physiol. Bioch. 43: 241-248, 2005.

De Gara L.: Ascorbate metabolism and plant growth: From germination to cell death. - In: Asard H., May J., Smirnoff N. (ed.): Vitamin C: Its Function and Biochemistry in Animals and Plants. Pp. 83-95. Taylor \& Francis, London 2004.

Demmig-Adams B., Adams III W.W.: Photoprotection and other responses of plants to high light stress. - Annu. Rev. Plant Phys. 43: 599-626, 1992.

Dong S., Jiang Y., Dong Y. et al.: A study on soybean responses to drought stress and rehydration. - Saudi J. Biol. Sci. 26: 2006-2017, 2019.

Farooq M., Wahid A., Kobayashi N. et al.: Plant drought stress: effects, mechanism and management. - Agron. Sustain. Dev. 29: 185-212, 2009.

Foyer C.H., Shigeoka S.: Understanding oxidative stress and antioxidant functions to enhance photosynthesis. - Plant Physiol. 15: 93-100, 2011.

Gechev T., Gadjiev I., Van Breusegem F. et al.: Hydrogen peroxide protects tobacco from oxidative stress by inducing a set of antioxidant enzymes. - Cell Mol. Life Sci. 59: 708714,2002

Gill S.S., Tuteja N.: Reactive oxygen species and antioxidant machinery in abiotic stress tolerance in crop plants. - Plant Physiol. Bioch. 48: 909-930, 2010.

Guo Y., Yu H., Kong D. et al.: Effects of gradual soil drought stress on the growth, biomass partitioning, and chlorophyll fluorescence of Prunus mongolica seedlings. - Turk. J. Biol. 39: 532-539, 2015.

Haworth M., Killi D., Materassi A. et al.: Impaired stomatal control is associated with reduced photosynthetic physiology in crop species grown at elevated $\left[\mathrm{CO}_{2}\right]$. - Front. Plant Sci. 7: $1568,2016$.

Hernández H., Dziembowski A., Taverner T. et al.: Subunit architecture of multimeric complexes isolated directly from cells. - EMBO Rep. 7: 605-610, 2006.

Huseynova I.M., Aliyeva D.R., Aliyev J.A.: Subcellular localization and responses of superoxide dismutase isoforms in local wheat varieties subjected to continuous soil drought. Plant Physiol. Bioch. 81: 54-60, 2014.

Huseynova I.M., Rustamova S.M., Suleymanov S.Y. et al.: Drought-induced changes in photosynthetic apparatus and antioxidant components of wheat (Triticum durum Desf.) varieties. - Photosynth. Res. 130: 215-223, 2016.

Huseynova I.M., Suleymanov S.Y., Aliyev J.A.: Structuralfunctional state of thylakoid membranes of wheat genotypes under water stress. - BBA-Bioenergetics 1767: 869-875, 2007.

Jangpromma N., Thammasirirak S., Jaisil P., Songsri P.: Effects of drought and recovery from drought stress on above ground and root growth, and water use efficiency in sugarcane (Saccharum officinarum L.). - Aust. J. Crop Sci. 6: 12981304, 2012.

Kalaji M.H., Nalborczyk E.: Gas exchange of barley seedlings growing under salinity stress. - Photosynthetica 25: 197-202, 1991.

Krieger-Liszkay A., Fufezan C., Trebst A.: Singlet oxygen production in photosystem II and related protection mechanism. - Photosynth. Res. 98: 551-564, 2008.

Krouma A.: Plant water relations and photosynthetic activity in three Tunisian chickpeas (Cicer arietinum L.) genotypes subjected to drought. - Turk. J. Agric. For. 34: 257-264, 2010.

Lambe T.W., Whitman R.V.: Description of an assemblage of particles. - In: Lambe T.W., Whitman R.V.: Soil Mechanics. Pp. 29-39. John Wiley \& Sons, Inc., New York-ChichesterBrisbane-Toronto-Singapore 1969.

Mahalingam R., Shah N., Scrymgeour A., Fedoroff N.V.: Temporal evolution of the Arabidopsis oxidative stress response. - Plant Mol. Biol. 57: 709-730, 2005.

Marček T., Hamow K.Á., Végh B. et al.: Metabolic response to drought in six winter wheat genotypes. - PLoS ONE 14: e0212411, 2019.

Munns R., Tester M.: Mechanisms of salinity tolerance. - Annu. Rev. Plant Biol. 59: 651-681, 2008.

Nogués S., Allen D.J., Morison J.I.L., Baker N.R.: Ultraviolet-B radiation effects on water relations, leaf development, and photosynthesis in droughted pea plants. - Plant Physiol. 117: 173-181, 1998.

Oh M.H., Safarova R.B., Eu Y.J. et al.: Loss of peripheral polypeptides in the stromal side of photosystem I by lightchilling in cucumber leaves. - Photoch. Photobio. Sci. 8: 535-541, 2009.

Pandey P., Ramegowda V., Senthil-Kumar M.: Shared and unique responses of plants to multiple individual stresses and stress combinations: physiological and molecular mechanisms. Front. Plant Sci. 6: 723, 2015.

Passardi F., Cosio C., Penel C., Dunand C.L.: Peroxidases have more functions than a Swiss army knife. - Plant Cell Rep. 24: 255-265, 2005.

Phillips K., Ludidi N.: Drought and exogenous abscisic acid alter hydrogen peroxide accumulation and differentially regulate the expression of two maize RD22-like genes. - Sci. Rep.-UK 7: 8821, 2017.

Porra R.J., Thompson W.A., Kriedemann P.E.: Determination of accurate extinction coefficients and simultaneous equations for assaying chlorophylls $a$ and $b$ extracted with four different solvents: verification of the concentration of chlorophyll standards by atomic absorption spectroscopy. BBA-Bioenergetics 975: 384-394, 1989.

Sallam A., Alqudah A.M., Dawood M.F.A. et al.: Drought stress tolerance in wheat and barley: advances in physiology, breeding and genetics research. - Int. J. Mol. Sci. 20: 3137, 2019.

Singleton V.L., Rossi J.A.: Colorimetry of total phenolics with 
phosphomolybdic phosphor-tungstic acid reagents. - Am. J. Enol. Vitic. 16: 144-158, 1965.

Sivakami V., Ramachandran B., Srivathsan J. et al.: Production and optimization of laccase and lignin peroxidase by newly isolated Pleurotus ostreatus LIG 19. - J. Microbiol. Biotech. Res. 2: 875-881, 2017.

Smirnoff N.: The role of active oxygen in the response of plants to water deficit and desiccation. - New Phytol. 125: 27-58, 1993.

Tari I., Csiszár J.: Effects on $\mathrm{NO}_{2}$ - or $\mathrm{NO}_{3}$-supply on polyamine accumulation and ethylene production of wheat roots at acidic and neutral $\mathrm{pH}$ : implications for root growth. - Plant Growth Regul. 40: 121-128, 2003.

Terashima I., Hanba Y.T., Tholen D., Niinemets Ü.: Leaf functional anatomy in relation to photosynthesis. - Plant Physiol. 155: 108-116, 2011.

Tsao R.: Chemistry and biochemistry of dietary polyphenols. Nutrients 2: 1231-1246, 2010.

Turner N.C.: Techniques and experimental approaches for the measurement of plant water status. - Plant Soil 58: 339-366, 1981.

Vass I.: Molecular mechanisms of photodamage in the photosystem II complex. - BBA-Bioenergetics 1817: 209217, 2012.

Vass I., Cser K.: Janus-faced charge recombination in photosystem
II photoinhibition. - Trends Plant Sci. 14: 200-205, 2009.

Wang Z., Li G., Sun H. et al.: Effects of drought stress on photosynthesis and photosynthetic electron transport chain in young apple tree leaves. - Biol. Open 7: bio.035279, 2018.

Wei T., Glomsrød S., Zhang T.: Extreme weather, food security and the capacity to adapt - the case of crops in China. - Food Secur. 9: 523-535, 2017.

von Wettstein D.: Chlorophyll-letale und der submikroskopische Formwechsel der Plastiden. - Exp. Cell Res. 12: 427-506, 1957. [In German] doi: 10.1016/0014-4827(57)90165-9.

Xu Z., Zhou G., Shimizu H.: Are plant growth and photosynthesis limited by pre-drought following re-watering in grass? - J. Exp. Bot. 60: 3737-3749, 2009.

Zivcak M., Brestic M., Balatova Z. et al.: Photosynthetic electron transport and specific photoprotective responses in wheat leaves under drought stress. - Photosynth. Res. 117: 529-546, 2013.

Zulfugarov I.S., Tovuu A., Kim J.H., Lee C.H.: Detection of reactive oxygen species in higher plants. - J. Plant Biol. 54: 351, 2011.

Zulfugarov I.S., Wu G., Tovuu A., Lee C.H.: Effect of oxygen on the non-photochemical quenching of vascular plants and potential oxygen deficiency in the stroma of PsbS-knock-out rice. - Plant Sci. 286: 1-6, 2019.

(C) The authors. This is an open access article distributed under the terms of the Creative Commons BY-NC-ND Licence. 